nephron

Practice
Nephron 2016;134:59-63

DOI: $10.1159 / 000448296$
Received: April 19, 2016

Accepted after revision: July 6, 2016

Published online: July 30, 2016

\title{
Renin-Angiotensin-Aldosterone System Antagonism and Polycystic Kidney Disease Progression
}

\author{
Chuan Kai Hian Chin Liang Lee Warren Thomas \\ Perdana University - Royal College of Surgeons in Ireland School of Medicine, Serdang, Malaysia
}

\section{Key Words}

Hypertension - Renal disease - Polycystic kidney disease .

Epidermal growth factor receptor - Aldosterone .

Renin-angiotensin system

\begin{abstract}
Autosomal Dominant Polycystic Kidney Disease (ADPKD) is a systemic disease characterised by the formation of multiple renal cysts that adversely affect renal function. ADPKD shows significant progression with age when complications due to hypertension are most significant. The activation of the renin-angiotensin-aldosterone system (RAAS) occurs in progressive kidney disease leading to hypertension. The RAAS system may also contribute to ADPKD progression by stimulating signalling pathways in the renal cyst cells to promote growth and deregulate epithelial transport. This mini review focuses on the contribution of the RAAS system to renal cyst enlargement and the potential for antagonists of the RAAS system to suppress cyst enlargement as well as control ADPKD-associated hypertension.
\end{abstract}

() 2016 S. Karger AG, Basel

E-Mail karger@karger.com

www.karger.com/nef

\section{Aetiology of Autosomal Dominant Polycystic Kidney Disease}

Autosomal Dominant Polycystic Kidney Disease (ADPKD) is a multisystem disease characterised by the development of multiple bilateral renal cysts and extrarenal manifestations such as cardiovascular abnormalities [1]. ADPKD affects 1 in 500 to 1 in 1,000 people with a significant decline in glomerular filtration rate (GFR) and renal function usually occurring by the 4 th decade of life [2]. ADPKD arises as a consequence of mutations in the $P K D 1$ and $P K D 2$ genes. Mutation of $P K D 1$ causes cyst development to occur at an earlier age, resulting in worse survival and more severe disease progression compared to $P K D 2$ mutation $[1,3]$. The proteins encoded by the PKD1 and PKD2 genes, polycystin-1 (PC1) and polycystin-2 (PC2), are both membrane-bound glycoproteins and constitute a subfamily of transient receptor potential (TRP) channels (TRPP1 and TRPP2, respectively) [2].

C.H. and C.L. contributed equally to the preparation of this review.
Dr. Warren Thomas

Perdana University - Royal College of Surgeons in Ireland School of Medicine, MAEPS Building, MARDI Complex Serdang, Selangor 43400 (Malaysia)

E-Mailwthomas@rcsi.ie 
PC1 is found in plasma membranes at focal adhesions, desmosomes, and adherens junction sites contributing to epithelial integrity and extracellular matrix interactions [1]. Both PC1 and PC2 are also present in the plasma membranes of the primary cilia and form a complex that is sensitive to filtrate flow in the renal tubule [1]. The development of ADPKD is characterised by enlarged kidneys, the formation of multiple fluid filled cysts and abnormal protein deposition [4]. Cellular abnormalities that contribute to cyst enlargement include abnormal fluid secretion across the epithelial cells and epithelial cell proliferation [2]. Increased hydrostatic pressure inside the cyst encourages expansion, while cellular proliferation induces de novo cyst formation [2]. Premature mortality in patients with ADPKD is most often attributable to cardiovascular disease associated with hypertension [2]. Hypertension control by inhibiting the renin-angiotensin-aldosterone system (RAAS) does not stop ADPKD patients from suffering end-stage renal disease (ESRD) [5], but it delays the onset of ESRD by $4-5$ years [6].

\section{Polycystin Mutation and Signalling in Polycystic Kidney Disease}

PC1 is a large, $460 \mathrm{kDa}$ (4302 aa), multi-domain, transmembrane protein that functions as a cation-permeable ion channel. PC2 is a smaller $110 \mathrm{kDa}$ (968 aa) transmembrane protein that interacts with the carboxy-terminus of PC1 and other TRP channels, and also the ryanodine receptor-2. The carboxy-termini of PC1 and PC2 form a heterotrimeric G-protein-binding domain that can initiate intracellular signalling cascades [1]. PC1 and PC2 are both integrated into a complex network of signalling pathways that can be deregulated in ADPKD. The structure of the renal cyst is the result of deregulated solute transport that promotes the accumulation of fluid within the lumen [4], and also the proliferation of renal tubule epithelial cells due to Epidermal growth factor receptor (EGFR) and transforming growth factor- $\alpha$ overexpression [7]. PC1 upregulates p21 (waf1) by activating the JAK-STAT pathway, resulting in cell-cycle arrest at G0/ G1 $[2,7]$. PC2 directly interacts with Id2, a member of the helix-loop-helix protein family to regulate cell cycle progression [7]. Mutation of PC1 and PC2 thus affects the proliferation potential of renal tubule cells. The overexpression and mislocation of EGFR in the apical membrane of cystic epithelial cells also stimulates cellular proliferation in the cyst cells through autophosphorylation of EGFR at Tyr416 [7].
The PC1/PC2 complex is a flow-dependent mechanosensor that regulates intracellular $\mathrm{Ca}^{2+}$ and cAMP levels [8]. Mutation of PC1 or PC2 can lead to lower cytoplasmic $\mathrm{Ca}^{2+}$ concentrations [9]. At low $\mathrm{Ca}^{2+}$ levels, there is an increase in adenylyl cyclase- 6 activity and a decrease phosphodiesterase activity, thereby increasing cAMP abundance $[3,7,9]$. cAMP is a strong mitogenic stimulant for cyst epithelial cells and is also implicated in the hyper-secretion associated with cyst formation. In normal individuals, the B-RAF proto-oncogene activity is inhibited by AKT. However, under $\mathrm{Ca}^{2+}$ restriction, there is low AKT activation resulting in increased B-RAF kinase activity [7]. Stimulation of the B-RAF/MEK/ERK pathway will promote fluid accumulation and epithelial cell growth mediated by cAMP, so potentiating renal failure [7]. In renal cyst epithelial cells, the basolateral $\mathrm{Na}^{+} / \mathrm{K}^{+}$ATPase mediates $\mathrm{Na}^{+}$extrusion in exchange for $\mathrm{K}^{+}$uptake via the sodium-potassium-chloride cotransporter 1 , which also drives basolateral $\mathrm{Cl}^{-}$entry [2]. Elevated PKA activity is associated with cAMP accumulation, and further stimulates $\mathrm{Na}^{+} /-\mathrm{K}^{+}$-ATPase activity that increases fluid accumulation in the cysts.

\section{Hypertension and Polycystic Kidney Disease}

Hypertension develops before the loss of kidney function in most adults with ADPKD [10, 11], and is an important risk factor for progression to ESRD, cardiovascular morbidity and mortality [5]. Severe hypertension in ADPKD can cause left ventricular hypertrophy and increase urinary albumin excretion, but this is normally observed before the changes in renal volume $[3,11]$. Aldosterone levels become elevated at an early stage in ADPKD patients and negatively correlate with a decline in plasma creatinine clearance; however, other studies have found that there is no direct correlation between RAAS activation and ADPKD [12]. The increasing use of antihypertensive therapy in ADPKD has been shown to reduce the incidence of ESRD [13]. Clinical trials have demonstrated variations in the efficacy of aggressive blood pressure control in delaying ESRD. A number of studies found that aggressive blood pressure control delays the progression of chronic kidney disease (CKD). These include the ESCAPE study, which found that aggressive blood pressure control in children with CKD resulted in better GFR and reduced progression to ESRD [14]; also a study conducted on an elderly population in Denmark concluded that a reduced incidence of ESRD in this population was associated with an increase in the prescription rates for 
anti-hypertensive drugs, especially RAAS blockade with angiotensin converting enzyme (ACE) inhibitors and angiotensin receptor blockade (ARB). Other studies such as the MDRD study found limited benefit in aggressive versus normal blood pressure control [15], while other studies found no benefit beyond that of normal blood pressure control $[16,17]$. ACE inhibition is used as the firstline treatment for ADPKD and a number of studies have found that it adequately achieves hypertension control in most patients [18-20]. However, a recently published large-scale study suggests that the delayed need for renal transplantation in ADPKD-associated ESRD is due to factors other than the renoprotective effects of hypertension control [21].

Short-term therapy with an ACE inhibitor improves renal blood flow, reduces proteinuria and delays renal failure [10]. Diuretics have equivalent efficacy to ACE inhibitors in controlling hypertension and are the first-line therapy where there has not been a significant loss in renal function [6]; however, patients treated with diuretics have a faster decline rate in GFR compared to those treated with ACE inhibitors [10, 11]. ACE inhibitors such as enalapril and ramipril effectively control blood pressure and proteinuria in hypertensive ADPKD patients but do not show any significant benefit in normotensive ADPKD patients [10]. Generally, ACE inhibitors are more effective than $\mathrm{Ca}^{2+}$ channel blockers such as dihydropyridine in controlling albuminuria, preserving creatinine clearance and reducing ventricular hypertrophy $[6,11]$. The use of ACE inhibitors alone may result in incomplete blockade of RAAS because angiotensin II may be produced through the chymase pathway within renal cysts, and so stimulate aldosterone release independent of ACE activity [10,22]. The use of ARB may circumvent angiotensin II activation at the renal cyst; however, lisinopril (ACE inhibitor) and telmisartan (angiotensin II receptor blocker) have similar efficacy in controlling blood pressure and lowering urinary aldosterone excretion [20].

\section{RAAS Involvement Beyond Hypertension Control}

RAAS activation contributes to the pathophysiology of ADPKD not only through the promotion of hypertension but also by directly stimulating the growth of renal cysts [5]. Angiotensin II and aldosterone both contribute to ADPKD-associated hypertension and potentially to cyst development. Angiotensin II promotes cellular proliferation and vascular hypertrophy [3], so stimulating cyst enlargement, local kidney ischemia and disrupting the renal architecture $[2,10]$. Renal ischemia can also lead to adenosine release that increases afferent renal nerve traffic [23]. The tubular dysfunction caused by structural changes in the kidney can result in $\mathrm{Na}^{+}$retention and vascular remodelling [3]. There is an increase in the urinary detection of monocyte chemoattractant protein-1 and altered growth of cardiovascular tissue, especially in the intima media of the carotid artery [3]. Such cardiovascular complications are a major mortality risk factor for ADPKD patients [11]. Renin protein and mRNA are found in ADPKD cyst fluid and may facilitate the local activation of the RAAS cascade in a manner that is ACE-independent [22]. This action is not controllable with ACE inhibitors and may represent an alternative target for therapeutic intervention. It is not clear what contribution is made by renin-independent RAAS activation and aldosterone release to ADPKD-associated hypertension.

The activation of the RAAS cascade culminates in aldosterone release from the adrenal cortex. The mineralocorticoid receptor (MR) is a ligand-dependent transcription factor that modulates the expression of target genes and initiates the activation of protein kinase signalling cascades. MR is expressed by the aldosterone-responsive cells of the distal nephron. The transcriptional action of aldosterone promotes the expression of the $\alpha$-subunit of the $\mathrm{Na}^{+} / \mathrm{K}^{+}$-ATPase to promote $\mathrm{Na}^{+}$conservation in normal tubular cells. In ADPKD, enhanced $\mathrm{Na}^{+} / \mathrm{K}^{+}$-ATPase activity may contribute to fluid secretion into the cyst and so promote cyst enlargement. Aldosterone also stimulates EGFR-coupled signalling cascades in MR-expressing cells [24]. The binding of aldosterone to MR can initiate a cSrc signalling cascade that activates EGFR through the release of heparin-bound EGF from the cell surface [25]. Activated EGFR stimulates renal fibroblast proliferation and the development of fibrotic lesions in the kidney [25]. EGFR transactivation by aldosterone can also promote proliferation in undifferentiated renal tubule cells [24]. Renal cyst formation is a combination of epithelial cell proliferation and ion transport dysregulation. Aldosterone can induce several signalling cascades, which include PKA, PKCa, PKD1, ERK1/2 mitogen-activated protein kinase, that enhance cell multiplication and modify ion transport activities in renal cells [24].

The HALT clinical trials included the objectives of evaluating the contributions of RAAS activation and blood pressure control on both the cardiovascular and renal manifestations of ADPKD [5]. Of particular importance was understanding whether controlling blood pressure at the very early stages of the disease, in advance of a significant decline in renal function may help to slow pro- 
gression to ESRD in younger patients. While aggressive blood pressure control did slow kidney enlargement and albuminuria, the study found that combined ACE inhibition and angiotensin II receptor antagonism did not attenuate the increase in kidney volume beyond that achieved by ACE inhibition alone [26]. Blood pressure control was most effective in slowing progression in male patients and patients with the most enlarged kidneys. The patients on dual therapy did have a reduced risk of hospitalization over the study and were less likely to develop kidney stones [26]. The study also looked at the effect of ACE inhibition and ARB on progression to ESRD and EGFR decline in advanced ADPKD, and found that dual therapy did not confer any benefit beyond that achieved with ACE inhibition alone [20]. Further investigation of the specific synergistic actions of ARB in combination with ACE antagonism may provide more information on how the intrarenal RAAS and localized activation of angiotensin in renal cysts contributes to cyst development independently of the systemic RAAS [12].

Since, combined ACE antagonism and ARB treatment have very limited synergistic action in attenuating ADPKD progression, the question remains whether direct antagonism of MR may be used effectively in combination with ACE antagonism. Animal models may also give us more information on the diverse actions of aldosterone in ADPKD. The Lewis polycystic kidney (LPK) rat model displays cardiovascular and renal pathophysiological changes that are associated with human ADPKD, including early elevation of plasma aldosterone and plasma creatinine [27]. MR antagonism with spironolactone achieved an effective control of hypertension in this animal model within 12 weeks. Spironolactone treatment also helped to restore renal function with the normalization of polydipsia, proteinuria and polyuria. Plasma creatinine levels were also reduced, thereby indicating a restoration of GFR. In spite of this enhancement in kidney function with spironolactone treatment, there was no impact on the gross morphology of the kidneys in the LPK rats [27]. Spironolactone had no significant effect on kidney volume, renal fibrosis or on cyst growth. This observation raises the question of how exactly is spironolactone stabilizing renal function in this model of ADPKD. The contribution of aldosterone to declining kidney function in the LPK model may also be different to its contribution in the human disease. The LPK phenotype arises because of mutation in the NIMArelated kinase 8 (Nek8) gene rather than in PC1 or PC2. Nek8 is a serine/threonine protein kinase that is associated with the primary cilium and co-immunoprecipi- tates with PC2 [28]. Nek8 phosphorylates PC2 and regulates the normal localization of PC1 and PC2 at the primary cilium. Consequently, the spectrum of deregulated signalling in the LPK model may be different to that seen in ADPKD, and the scope for aldosterone to accelerate disease progression may rely upon alternative mechanisms in different signalling backgrounds depending on whether PC1 and PC2 are mutated, improperly phosphorylated or mislocated. A recent study has found that activation of an intrarenal renin-angiotensin pathway is stimulated on PC1 knock-out and primary cilium dysfunction [29].

\section{Conclusion}

The importance of antagonizing the RAAS system to control ADPKD progression and associated hypertension is evident; however, we need to understand better how aldosterone antagonism, in particular, can help to directly mitigate the renal effects of this disease. Aldosterone participates in a broad spectrum of signalling actions in renal tubular cells, which include the regulation of transporter activity, cell differentiation and growth. There is considerable overlap between the signalling cascades coupled to the normal function of the PC1 and PC2 proteins, and the actions of aldosterone in the distal nephron. The full contribution of systemic or intrarenal RAAS over-stimulation and the resultant deregulated signalling and transporter activity in ADPKD cyst cells remains to be established.

\section{Disclosure Statement}

The authors declare no conflict of interest.

References

1 Irazabal MV, Torres VE: Experimental therapies and ongoing clinical trials to slow down progression of ADPKD. Curr Hypertens Rev 2013:9:44-59.

2 Takiar V, Caplan MJ: Polycystic kidney disease: pathogenesis and potential therapies. Biochim Biophys Acta 2011;1812:1337-1343.

3 Ratnam S, Nauli SM: Hypertension in autosomal dominant polycystic kidney disease: a clinical and basic science perspective. Int J Nephrol Urol 2010;2:294-308.

4 Zheleznova NN, Wilson PD, Staruschenko A Epidermal growth factor-mediated proliferation and sodium transport in normal and PKD epithelial cells. Biochim Biophys Acta 2011;1812:1301-1313.
62 
5 Torres VE, Chapman AB, Perrone RD, Bae KT, Abebe KZ, Bost JE, Miskulin DC, Steinman TI, Braun WE, Winklhofer FT, Hogan MC, Oskoui FR, Kelleher C, Masoumi A, Glockner J, Halin NJ, Martin DR, Remer E, Patel N, Pedrosa I, Wetzel LH, Thompson PA, Miller JP, Meyers CM, Schrier RW; HALT PKD Study: Analysis of baseline parameters in the HALT polycystic kidney disease trials. Kidney Int 2012;81:577-585.

-6 Sans-Atxer L, Torra R, Fernández-Llama P: Hypertension in autosomal-dominant polycystic kidney disease (ADPKD). Clin Kidney J 2013;6:457-463.

7 Sun Y, Zhou H, Yang BX: Drug discovery for polycystic kidney disease. Acta Pharmacol Sin 2011;32:805-816.

8 Chebib FT, Sussman CR, Wang X, Harris PC, Torres VE: Vasopressin and disruption of calcium signalling in polycystic kidney disease. Nat Rev Nephrol 2015;11:451-464.

9 Ong AC, Harris PC: A polycystin-centric view of cyst formation and disease: the polycystins revisited. Kidney Int 2015;88:699-710.

-10 Halvorson CR, Bremmer MS, Jacobs SC: Polycystic kidney disease: inheritance, pathophysiology, prognosis, and treatment. Int J Nephrol Renovasc Dis 2010;3:69-83.

11 Schrier RW: Hypertension and autosomal dominant polycystic kidney disease. Am J Kidney Dis 2011;57:811-813.

-12 Lawson CR, Doulton TW, MacGregor GA: Autosomal dominant polycystic kidney disease: role of the renin-angiotensin system in raised blood pressure in progression of renal and cardiovascular disease. J Renin Angiotensin Aldosterone Syst 2006;7:139-145.

13 Heaf JG, Wehberg S: Reduced incidence of end stage renal disease among the elderly in Denmark: an observational study. BMC Nephrol 2012;13:131.

14 ESCAPE Trial Group, Wühl E, Trivelli A, Picca S, Litwin M, Peco-Antic A, Zurowska A, Testa S, Jankauskiene A, Emre S, CaldasAfonso A, Anarat A, Niaudet P, Mir S, Bakkaloglu A, Enke B, Montini G, Wingen AM, Sallay P, Jeck N, Berg U, Caliskan S, Wygoda S, Hohbach-Hohenfellner K, Dusek J, Urasinski T, Arbeiter K, Neuhaus T, Gellermann J, Drozdz D, Fischbach M, Möller K, Wigger M, Peruzzi L, Mehls O, Schaefer F: Strict bloodpressure control and progression of renal failure in children. N Engl J Med 2009;361:1639_ 1650.
15 Klahr S, Levey AS, Beck GJ, Caggiula AW, Hunsicker L, Kusek JW, Striker G: The effects of dietary protein restriction and blood-pressure control on the progression of chronic renal disease. Modification of diet in renal disease study group. N Engl J Med 1994;330:877-884.

16 Ruggenenti P, Perna A, Loriga G, Ganeva M, Ene-Iordache B, Turturro M, Lesti M, Perticucci E, Chakarski IN, Leonardis D, Garini G, Sessa A, Basile C, Alpa M, Scanziani R, Sorba G, Zoccali C, Remuzzi G; REIN-2 Study Group: Blood-pressure control for renoprotection in patients with non-diabetic chronic renal disease (REIN-2): multicentre, randomised controlled trial. Lancet 2005;365: 939-946.

17 Wright JT Jr, Bakris G, Greene T, Agodoa LY, Appel LJ, Charleston J, Cheek D, Douglas-Baltimore JG, Gassman J, Glassock R, Hebert L, Jamerson K, Lewis J, Phillips RA, Toto RD, Middleton JP, Rostand SG; African American Study of Kidney Disease and Hypertension Study Group: Effect of blood pressure lowering and antihypertensive drug class on progression of hypertensive kidney disease: results from the AASK trial. JAMA 2002;288:2421-2431.

18 Chapman AB, Devuyst O, Eckardt KU, Gansevoort RT, Harris T, Horie S, Kasiske BL, Odland D, Pei Y, Perrone RD, Pirson Y, Schrier RW, Torra R, Torres VE, Watnick T, Wheeler DC; Conference Participants: Autosomal-dominant polycystic kidney disease (ADPKD): executive summary from a kidney disease: improving global outcomes (KDIGO) controversies conference. Kidney Int 2015;88: 17-27.

$19 \mathrm{Ku}$ E, Glidden DV, Johansen KL, Sarnak M, Tighiouart H, Grimes B, Hsu CY: Association between strict blood pressure control during chronic kidney disease and lower mortality after onset of end-stage renal disease. Kidney Int 2015;87:1055-1060.

20 Torres VE, Abebe KZ, Chapman AB, Schrier RW, Braun WE, Steinman TI, Winklhofer FT, Brosnahan G, Czarnecki PG, Hogan MC, Miskulin DC, Rahbari-Oskoui FF, Grantham JJ, Harris PC, Flessner MF, Moore CG, Perrone RD; HALT-PKD Trial Investigators: Angiotensin blockade in late autosomal dominant polycystic kidney disease. N Engl J Med 2014:371:2267-2276.

21 Spithoven EM, Kramer A, Meijer E, Orskov B, Wanner C, Caskey F, Collart F, Finne P, Fogarty DG, Groothoff JW, Hoitsma A, Nogier
MB, Postorino M, Ravani P, Zurriaga O, Jager KJ, Gansevoort RT; ERA-EDTA Registry; EuroCYST Consortium; WGIKD; EuroCYST Consortium; WGIKD: Analysis of data from the ERA-EDTA registry indicates that conventional treatments for chronic kidney disease do not reduce the need for renal replacement therapy in autosomal dominant polycystic kidney disease. Kidney Int 2014;86: 1244-1252.

22 Rahbari-Oskoui F, Williams O, Chapman A: Mechanisms and management of hypertension in autosomal dominant polycystic kidney disease. Nephrol Dial Transplant 2014;29: 2194-2201.

-23 Klein IH, Ligtenberg G, Oey PL, Koomans HA, Blankestijn PJ: Sympathetic activity is increased in polycystic kidney disease and is associated with hypertension. J Am Soc Nephrol 2001;12:2427-2433.

24 McEneaney V, Harvey BJ, Thomas W: Aldosterone rapidly activates protein kinase $\mathrm{D}$ via a mineralocorticoid receptor/EGFR trans-activation pathway in the M1 kidney CCD cell line. J Steroid Biochem Mol Biol 2007;107: 180-190.

25 Yan Y, Ma L, Zhou X, Ponnusamy M, Tang J, Zhuang MA, Tolbert E, Bayliss G, Bai J, Zhuang S: Src inhibition blocks renal interstitial fibroblast activation and ameliorates renal fibrosis. Kidney Int 2016;89:68-81.

26 Schrier RW, Abebe KZ, Perrone RD, Torres VE, Braun WE, Steinman TI, Winklhofer FT, Brosnahan G, Czarnecki PG, Hogan MC, Miskulin DC, Rahbari-Oskoui FF, Grantham JJ, Harris PC, Flessner MF, Bae KT, Moore CG, Chapman AB; HALT-PKD Trial Investigators: Blood pressure in early autosomal dominant polycystic kidney disease. N Engl J Med 2014;371:2255-2266.

27 Jeewandara TM, Ameer OZ, Boyd R, Wyse BF, Underwood CF, Phillips JK: Protective cardiorenal effects of spironolactone in a rodent model of polycystic kidney disease. Clin Exp Pharmacol Physiol 2015;42:353-360.

28 Sohara E, Luo Y, Zhang J, Manning DK, Beier DR, Zhou J: Nek8 regulates the expression and localization of polycystin-1 and polycystin-2. J Am Soc Nephrol 2008;19:469-476.

29 Saigusa T, Dang Y, Bunni MA, Amria MY, Steele SL, Fitzgibbon WR, Bell PD: Activation of the intrarenal renin-angiotensin-system in murine polycystic kidney disease. Physiol Rep 2015;3:pii:e12405.
Polycystic Kidney Disease and Hypertension 